\title{
Epigenetic Age Acceleration Assessed with Human White-Matter Images
}

\author{
๑Karen Hodgson, ${ }^{1}$ Melanie A. Carless, ${ }^{2}$ Hemant Kulkarni, ${ }^{3}$ Joanne E. Curran, ${ }^{3}$ Emma Sprooten, ${ }^{4}$ Emma E. Knowles, ${ }^{1}$ \\ @Samuel Mathias, ${ }^{1}$ Harald H.H. Göring, ${ }^{3}$ Nailin Yao, ${ }^{1}$ @Rene L. Olvera, ${ }^{5}$ Peter T. Fox, ${ }^{6}$ Laura Almasy, ${ }^{3}$ Ravi Duggirala, ${ }^{3}$ \\ John Blangero, ${ }^{3}$ and $\odot$ David C. Glahn ${ }^{1,7}$ \\ 'Department of Psychiatry, Yale University School of Medicine, New Haven, Connecticut 06511, 2Department of Genetics, Texas Biomedical Research \\ Institute, San Antonio, Texas 78227, ${ }^{3}$ South Texas Diabetes and Obesity Institute, University of Texas Rio Grande Valley School of Medicine, Brownsville, \\ Texas 78530, ${ }^{4}$ Department of Psychiatry, Icahn Medical Institute, New York, New York 10029, ${ }^{5}$ Department of Psychiatry, University of Texas Health \\ Science Center San Antonio, San Antonio, Texas 78229, ${ }^{6}$ Research Imaging Institute, University of Texas Health Science Center San Antonio, San Antonio, \\ Texas 78229, and ${ }^{7}$ Olin Neuropsychiatry Research Center, Institute of Living, Hartford Hospital, Hartford, Connecticut 06106
}

The accurate estimation of age using methylation data has proved a useful and heritable biomarker, with acceleration in epigenetic age predicting a number of age-related phenotypes. Measures of white matter integrity in the brain are also heritable and highly sensitive to both normal and pathological aging processes across adulthood. We consider the phenotypic and genetic interrelationships between epigenetic age acceleration and white matter integrity in humans. Our goal was to investigate processes that underlie interindividual variability in age-related changes in the brain. Using blood taken from a Mexican-American extended pedigree sample $(n=628$; age $=$ 23.28 -93.11 years), epigenetic age was estimated using the method developed by Horvath (2013). For $n=376$ individuals, diffusion tensor imaging scans were also available. The interrelationship between epigenetic age acceleration and global white matter integrity was investigated with variance decomposition methods. To test for neuroanatomical specificity, 16 specific tracts were additionally considered. We observed negative phenotypic correlations between epigenetic age acceleration and global white matter tract integrity $\left(\rho_{\text {pheno }}=\right.$ $-0.119, p=0.028)$, with evidence of shared genetic $\left(\rho_{\text {gene }}=-0.463, p=0.013\right)$ but not environmental influences. Negative phenotypic and genetic correlations with age acceleration were also seen for a number of specific white matter tracts, along with additional negative phenotypic correlations between granulocyte abundance and white matter integrity. These findings (i.e., increased acceleration in epigenetic age in peripheral blood correlates with reduced white matter integrity in the brain and shares common genetic influences) provide a window into the neurobiology of aging processes within the brain and a potential biomarker of normal and pathological brain aging.

Key words: aging; epigenetics; genetics; white matter integrity

Significance Statement

Epigenetic measures can be used to predict age with a high degree of accuracy and so capture acceleration in biological age, relative to chronological age. The white matter tracts within the brain are also highly sensitive to aging processes. We show that increased biological aging (measured using epigenetic data from blood samples) is correlated with reduced integrity of white matter tracts within the human brain (measured using diffusion tensor imaging) with data from a large sample of Mexican-American families. Given the family design of the sample, we are also able to demonstrate that epigenetic aging and white matter tract integrity also share common genetic influences. Therefore, epigenetic age may be a potential, and accessible, biomarker of brain aging.

\section{Introduction}

The human population is aging at a rapid rate as the number of older persons have increased sharply within recent years (United
Nations Department of Economic and Social Affairs Population Division, 2015). Between 2014 and 2060, the U.S. population of individuals over 65 year is expected to more than double, from 
46.2 million to 98 million (Mather et al., 2015). An aging population brings with it an increasing urgency to understand the processes that lead to normal age-related decline in both physical and mental abilities as well as in age-associated illness. Given individual differences in the rate of age-related changes, the identification of biomarkers for vulnerability to deleterious aging effects and improved understanding of the mechanisms involved in healthy aging is invaluable. Among the more successful agerelated biomarkers to date are indices based upon epigenetic variation (Fraga et al., 2005; Horvath et al., 2012; Hannum et al., 2013; Horvath, 2013; Teschendorff et al., 2013; Weidner et al., 2014; Jones et al., 2015), particularly the pan-tissue "epigenetic clock" developed by Horvath (2013). This clock is highly accurate in predicting age across a large number of different tissues, can be applied to data obtained for both the $27 \mathrm{~K}$ and $450 \mathrm{~K}$ Illumina Methylation BeadChips and has been shown to be predictive of a number of age-associated phenotypes (Horvath and Ritz, 2015; Marioni et al., 2015a, b).

The brain is of particular interest in aging, as cognitive decline is one of the greatest health threats of old age (van Boxtel et al., 1998). Additionally, the brain indirectly regulates aging responses in various organs (Bishop et al., 2010). Among in vivo measures of brain aging, white matter tract integrity (as indexed by fractional anisotropy [FA] from diffusion weighted MR images) is highly sensitive to both healthy and pathological aging (Moseley, 2002; Sullivan and Pfefferbaum, 2006; Giorgio et al., 2010; Teipel et al., 2010; Cox et al., 2016). Although FA measures are heritable (Jahanshad et al., 2013; Sprooten et al., 2014; Kochunov et al., 2015) and known to decline with age, Glahn et al. (2013) showed that genetic influences on white matter do not vary as a factor of age (no evidence for a gene by age interaction was found), in contrast with analyses for cognitive traits. Additionally, the specific biological mechanisms that influence white matter integrity are not yet known.

To determine whether variation in white matter integrity is associated with acceleration in epigenetic age, we analyzed their interrelationship in large, randomly ascertained pedigrees. Specifically, we calculated an estimator of epigenetic age for each subject, using a weighted average across 353 CpG sites (after Horvath) captured from blood samples. We then determined whether variation in this epigenetic age was correlated with variation in tract-based FA measures while controlling familial relationships (and after accounting for covariates of age, sex, and blood cell composition effects on epigenetic profiles). By using a family-based cohort, we considered not only phenotypic relationships, but also any underlying genetic correlations between these two heritable traits. We observed that accelerated epigenetic age was associated with reduced white matter integrity both globally and in a number of specific brain regions. This relationship was underpinned by shared genetic influences. We additionally investigated the relationship between epigenetic age acceleration and white matter hyperintensities, to consider the specificity of the relationship with FA.

\section{Materials and Methods}

Subjects. The Genetics of Brain Structure and Function study includes individuals recruited from large multigeneration Mexican-American families within San Antonio, Texas (Olvera et al., 2011). This is a subset of the San Antonio Family Study cohort, which was recruited pseudorandomly with the constraints that participants must live within the San Antonio region, be Mexican-American in ancestry, and have at least six first-degree relatives (Mitchell et al., 1996; Puppala et al., 2006). In this study, we considered the 628 individuals with epigenetic age estimates, from 38 families (containing between 2-72 subjects, mean pedigree size $=14.25$ ) and an additional 14 genetically unrelated spouses. Of these 628 subjects with epigenetic age estimates, 376 had diffusion tensor imaging (DTI) data also available. DTI scans were obtained on average 3.77 years (SD 1.61 years) after blood samples were drawn for the assessment of epigenetic methylation profiles. In all cases, the chronological age used is age at blood draw, but results are not substantially altered if this is substituted for age at DTI scan. Numbers reflect final totals after any individuals were removed during QC steps.

Epigenetic measures. Full details of methylation assays and preprocessing were described previously (Kulkarni et al., 2015). Briefly, peripheral blood samples were used to obtain 500 ng of DNA. Bisulfite conversion was performed; then methylation profiling was undertaken using the Infinium HumanMethylation450 BeadChip assay (Illumina). At each $\mathrm{CpG}$ site, methylation was quantified on a scale from 0 (fully unmethylated) to 1 (fully methylated). Probes that were located on the sex chromosomes $(n=11,648)$, in non-CpG loci $(n=2994)$, or contained SNPs $(n=65)$ were excluded.

Calculating epigenetic age and age acceleration. The method developed by Horvath (2013) was used to calculate epigenetic age for each individual using the available online age calculator (https://dnamage.genetics. ucla.edu). This approach uses DNA methylation levels of 353 agepredictive CpG sites (originally identified by Horvath, 2013, using an elastic net penalized regression model). This method has been shown to generate a predicted epigenetic age (labeled "DNAmAge" within the software) that correlates highly with chronological age and is accurate across a wide range of different cell and tissue types (Horvath, 2013), as well as being predictive of a number of age-associated phenotypes (Horvath and Ritz, 2015; Marioni et al., 2015a, b). Thus, epigenetic age, as captured with this method, is proposed to indicate the methylation-based age of a tissue.

In each model, the covariates of age, sex, age $\times$ sex, age ${ }^{2}$, age $^{2} \times$ sex, and the cell count estimates described below were applied to the epigenetic age ("DNAmAge") variable. Throughout the manuscript, we describe the variation in the epigenetic age that remains after accounting for these covariates as epigenetic age acceleration. Increased epigenetic age acceleration indicates that the individual is epigenetically older than would be expected given their chronological age and other covariates.

The epigenetic age calculator also calculated the predicted sex of each sample; 5 samples were excluded because of inconsistencies in reported and epigenetically predicted sex.

Estimating cell composition of whole blood samples. To consider the cell composition of the whole blood samples, previously developed methods for estimated cell counts (Houseman et al., 2012; Horvath, 2013) were used within the epigenetic calculator software, as recommended by Horvath (2013). Estimates of $\mathrm{CD} 8{ }^{+} \mathrm{CD} 28^{-} \mathrm{CD} 45 \mathrm{RA}{ }^{-} \mathrm{T}$ cells, naive CD8 T cells, CD4 T cells, plasmablasts, natural killer cells, monocytes, and granulocytes were obtained and included as covariates when calculating epigenetic age acceleration.

Neuroimaging measures. White matter integrity was assessed using DTI. Scanning was performed using a multichannel head coil and Trio 3T system (Siemens) at the Research Imaging Institute, University of Texas Health Science Center (San Antonio, TX). The DTI acquisition protocol used a single-shot spin-echo, EPI sequence with a spatial resolution of $1.7 \times 1.7 \mathrm{~mm}$ (repetition time/echo time $=8000 / 87 \mathrm{~ms}$, FOV $200 \mathrm{~mm}, 55$ nonparallel gradient directions $\mathrm{b}=700 \mathrm{~s} / \mathrm{mm}^{2}$ and three non-diffusion-weighted images $b=0$ ).

DTI scans were preprocessed using standard FSL pipelines (http://fsl. fmrib.ox.ac.uk/fsl/fslwiki/FDT). The resulting FA images were processed with tract-based spatial statistics (Smith et al., 2006). Images were nonlinearly registered to standard space, then averaged, and skeletonized to create a study-specific tract-based spatial statistics template (binarized at FA $>0.2$ ). Next, the maximum nearby FA voxel was projected onto the skeleton, resulting in one skeleton image per subject, reflecting FA values of the centers of the white matter structure for that individual. The mean FA from the whole white matter skeleton was extracted for each individual to give a global measure of white matter integrity. In addition, for each subject, mean FA values were extracted from each region and averaged across hemispheres for 16 specific tracts as defined by the Johns Hopkins White Matter Atlas (Mori et al., 2008). 
Fluid Attenuated Inversion Recovery images were obtained using the following parameters: TR/TE/TI/flip angle/ETL $=5 \mathrm{~s} / 353 \mathrm{~ms} / 1.8 \mathrm{~s} / 180^{\circ} /$ 221. Preprocessing involved the removable of nonbrain tissue, registration to the Talairach frame, and RF inhomogeneity correction. Then, an experienced neuroanatomist used in-house software (http://ric.uthscsa. edu/mango) to manually delineate white matter hyperintensities. This was completed with high $(r>0.9)$ test-retest reliability. These methods have been previously described in detail (Kochunov et al., 2010). Whole brain white matter hyperintensity volumes were used.

Statistical analysis. Using SOLAR (Sequential Oligogenic Linkage Analysis Routines), first the heritability of epigenetic age acceleration and each DTI trait was calculated. As the global measure of white matter integrity includes FA estimates across the brain, including more peripheral FA not captured by the 16 specific Johns Hopkins White Matter Atlas tracts, our primary outcome was the phenotypic correlation between epigenetic age acceleration and global white matter tract integrity, as determined within a bivariate model. This phenotypic relationship was decomposed to give genetic and environmental correlations. To assess neuroanatomical specificity, we then examined the relationship between epigenetic age acceleration and each of the 16 specific DTI tracts. Phenotypic correlations where $p<0.05$ were considered suggestive, and we applied a false discovery rate (FDR) correction (Benjamini and Hochberg, 1995) across the 16 specific tracts to account for multiple hypothesis testing (phenotypic correlations where FDR $<0.05$ was considered significant). All phenotypic correlations reaching at least suggestive significance were decomposed into genetic and environmental components.

Covariates in each model were age, sex, age $\times$ sex, age ${ }^{2}$, and age ${ }^{2} \times$ sex. Additionally, for epigenetic age acceleration, covariates of cell marker abundance were also applied (given the effect of cell heterogeneity on methylation data from whole blood).

\section{Results}

Epigenetic age

The estimated epigenetic age ("DNAmAge") of the sample ranged between 20.42 and 86.48 years (mean \pm SD, $48.12 \pm$ 11.49 years). At the time of blood draw, the chronological age of the sample ranged between 23.28 and 93.11 years $(45.45 \pm 13.30$ years). These two variables show a high correlation $\left(\rho_{\text {pheno }}=\right.$ $0.932, p=1.82 \times 10^{-285}$ ), as depicted in Figure $1 \mathrm{~A}$. The average difference between epigenetic and chronological age is 2.67 years (so epigenetic age is typically higher than chronological age in this sample) When we consider females and males separately, the average difference between epigenetic and chronological age is 2.47 years in females and 3.04 years in males; but this difference does not reach significance in our sample (previous findings suggest the epigenetic aging rate of men is significantly higher than for women) (Horvath et al., 2016a). For the whole sample, the median absolute difference between epigenetic and chronological age is 3.68 years, indicating that epigenetic and chronological age differs by $<3.68$ years for $50 \%$ of the subjects. However, for some individuals, differences between epigenetic and chronological age were substantial; $7.00 \%$ of the sample have an absolute difference of $>10$ years, and the maximum absolute difference between epigenetic and chronological age is 15.96 years.

\section{Epigenetic age acceleration index}

As detailed in Materials and Methods, the epigenetic age acceleration measure captures variation in epigenetic age ("DNAmAge") estimates, after accounting for covariates of chronological age, sex, age $\times$ sex, age $e^{2}$, and age $e^{2} \times$ sex, and cell composition in the blood. Positive values for epigenetic age acceleration indicate that an individual is epigenetically older than would be expected given these covariates, whereas negative values for epigenetic age acceleration indicate that an individual is epigenetically younger than expected. The measure is (by definition) uncorrelated with age. The distribution of epigenetic age acceleration within the sample is shown in Figure $1 B$, and the trait heritability estimate $\left(n=628, \mathrm{~h}^{2}=0.374, p=6.00 \times 10^{-7}, \mathrm{SE}=0.097\right)$ is in line with previous findings (Horvath, 2013; Marioni et al., 2015a; Lu et al., 2016). The proportion of variance accounted for by covariates in this model was 0.864 . We note that, in our sample, sex is not a significant covariate $(p=0.305)$ but is retained in the model nonetheless.

\section{White matter integrity and chronological age}

As has been previously shown, global white matter tract integrity was heritable in the sample $\left(\mathrm{h}^{2}=0.506, p=1.65 \times 10^{-5}\right)$. There was no evidence of sex differences in white matter tract integrity ( $\operatorname{sex}$ is not a significant covariate in the model, $p=0.597$ ), but we did observe a strong age effect; age was a significant covariate in the heritability model $\left(p=2.75 \times 10^{-13}\right)$ and there was a significant negative phenotypic correlation between global white matter integrity and age (Fig. 2). For the specific white matter tracts, all were heritable and all, except the cingulum (hippocampus), showed a significant negative phenotypic correlation with age. Statistics are shown in Table 1.

\section{Global white matter integrity and epigenetic age acceleration}

Given that the integrity of white matter is correlated across the brain and the global measure of white matter integrity includes peripheral FA estimates not captured in specific tracts, we used the global measure as an omnibus test, before examining specific tract-based variation. The global index was negatively phenotypically correlated $\left(\rho_{\text {pheno }}=-0.119, p=0.028\right)$ with the bloodbased epigenetic index of age acceleration, showing that individuals with blood samples that are epigenetically older than expected have reduced global FA in the brain. We decomposed this phenotypic correlation into genetic and environmental influences, finding evidence for common genetic $\left(\rho_{\text {gene }}=-0.460\right.$, $p=0.014)$, but not environmental $\left(\rho_{\mathrm{env}}=0.222, p=0.174\right)$, factors. As the genetic correlation was negative, it suggests that the genes that increase epigenetic age acceleration in blood are also associated with reduced white matter integrity in brain.

Both diabetes and hypertension are age-linked traits that have been associated with changes in white matter tract integrity. We confirmed that the relationship between epigenetic age acceleration and global white matter tract integrity remained significant when covarying for either diabetes $\left(\rho_{\text {pheno }}=-0.112, p=0.038\right)$ or hypertension $\left(\rho_{\text {pheno }}=-0.116, p=0.031\right)$.

\section{Specific tract-based white matter integrity and epigenetic age acceleration}

To determine neuroanatomic specificity of this effect, we next examined FA in individual tracts. Seven of the 16 tracts were phenotypically correlated with epigenetic age acceleration where $p<0.05$ (the anterior and posterior corona radiata, the genu, body and splenium of the corpus callosum, the posterior thalamic radiation, and the superior frontal-occiptal fasciculus). Three of these (the posterior corona radiata and the body and splenium of the corpus callosum) remain significant when using an FDR correction of $<0.05$ across all 16 tracts. Results are shown in Table 1. In all cases, the phenotypic relationship between age acceleration and white matter integrity is negative, matching the direction of effects observed with the global white matter measure.

For the seven tracts where the phenotypic correlation with epigenetic age acceleration reached the nominal significance threshold of $p<0.05$, we decomposed the correlations into genetic and environmental influences. Five tracts gave genetic 


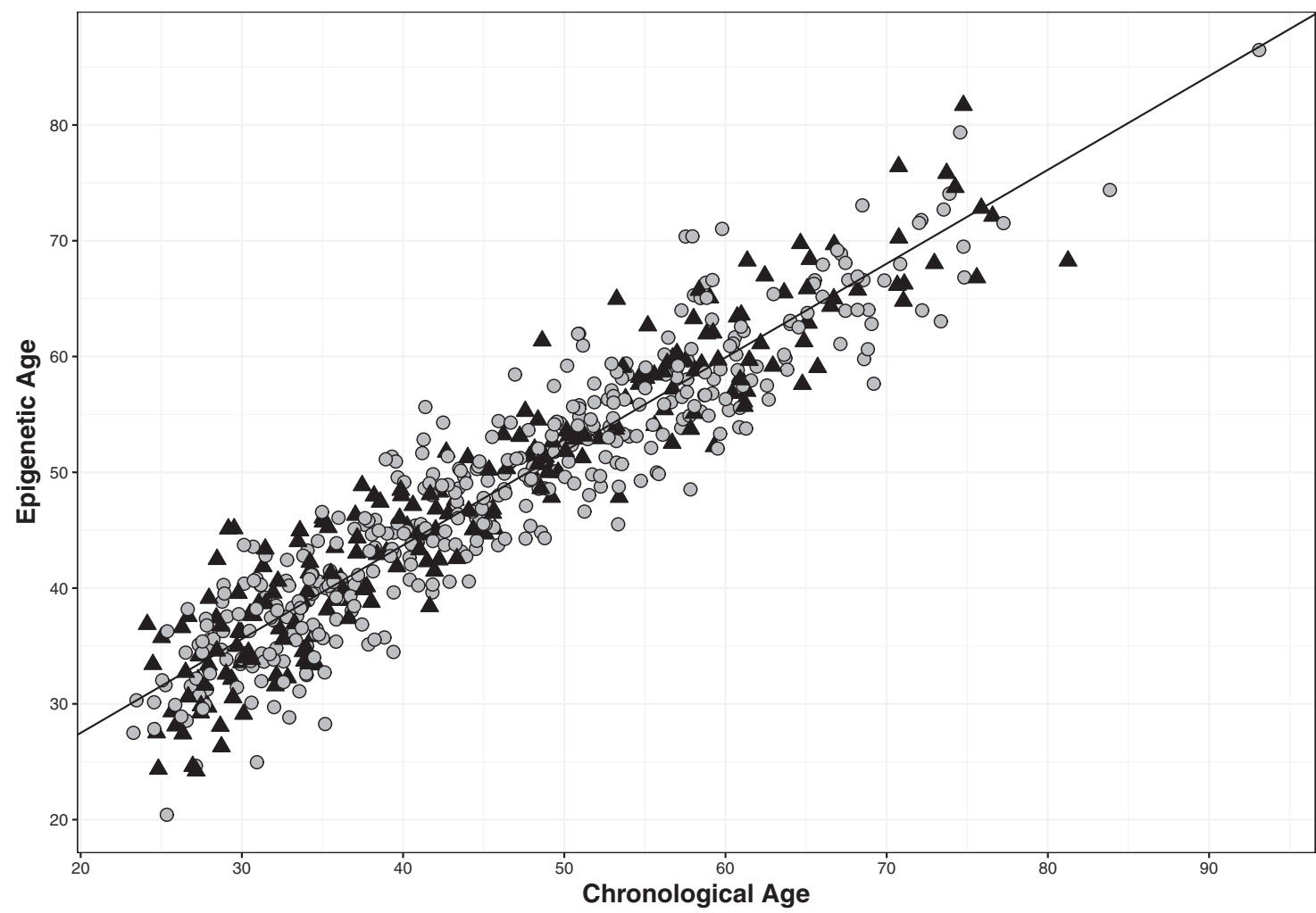

Sex OF $\boldsymbol{\Delta} M$

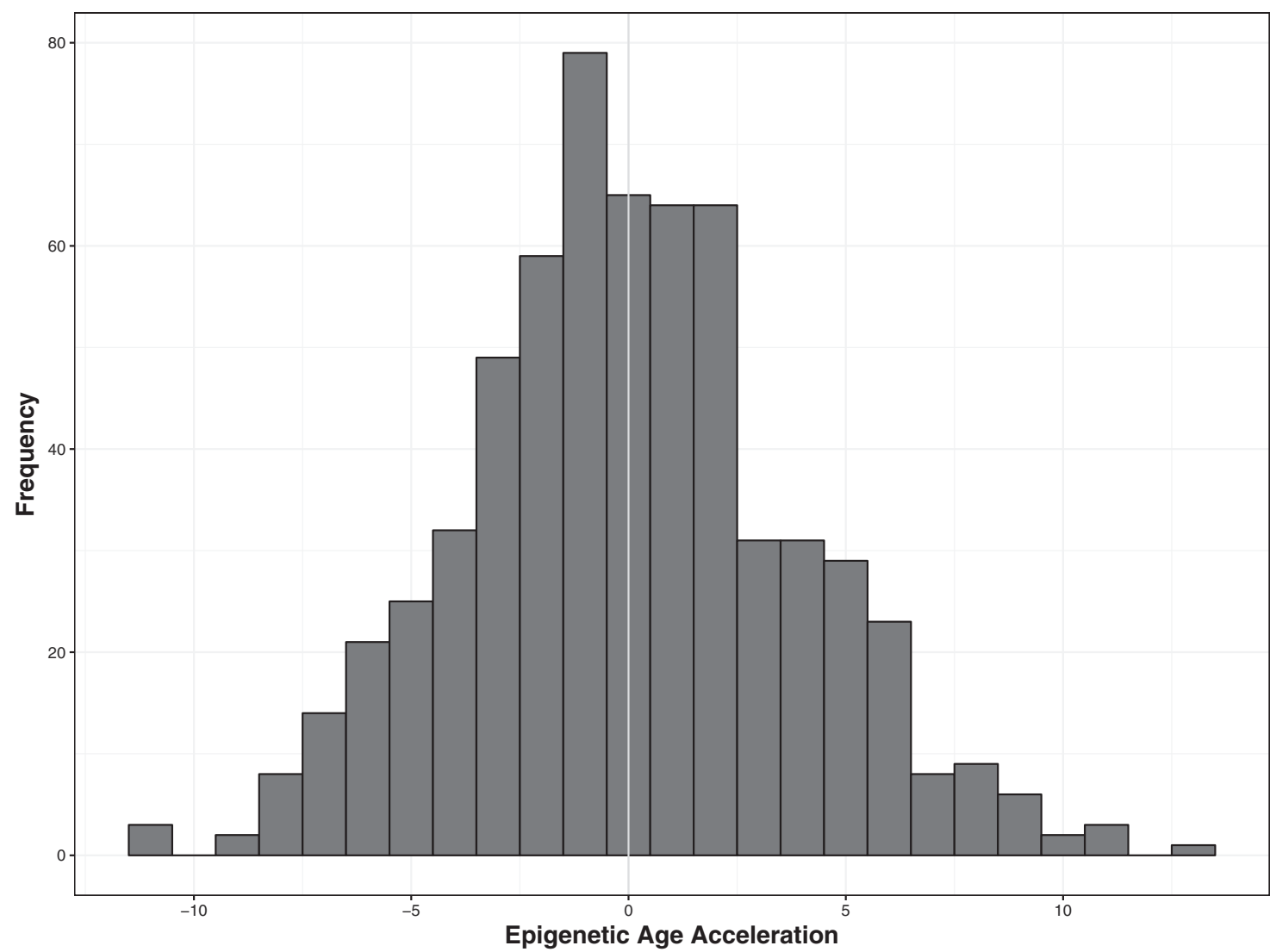

Figure 1. Epigenetic age measures. Top, Chronological age compared with epigenetic age estimates; correlation slope shown. Light gray represents females. Dark gray represents males. Bottom, Distribution of epigenetic age acceleration measure (i.e., epigenetic age covarying for age, sex, age $\times$ sex, age $^{2}$, and age ${ }^{2} \times$ sex, and cell composition in blood). If values are $>0$ (to the right of the vertical line), this indicates individuals have epigenetic age estimates that are older than would be expected given the covariates; if values are $<0$, this indicates that epigenetic age estimates are younger than expected. 


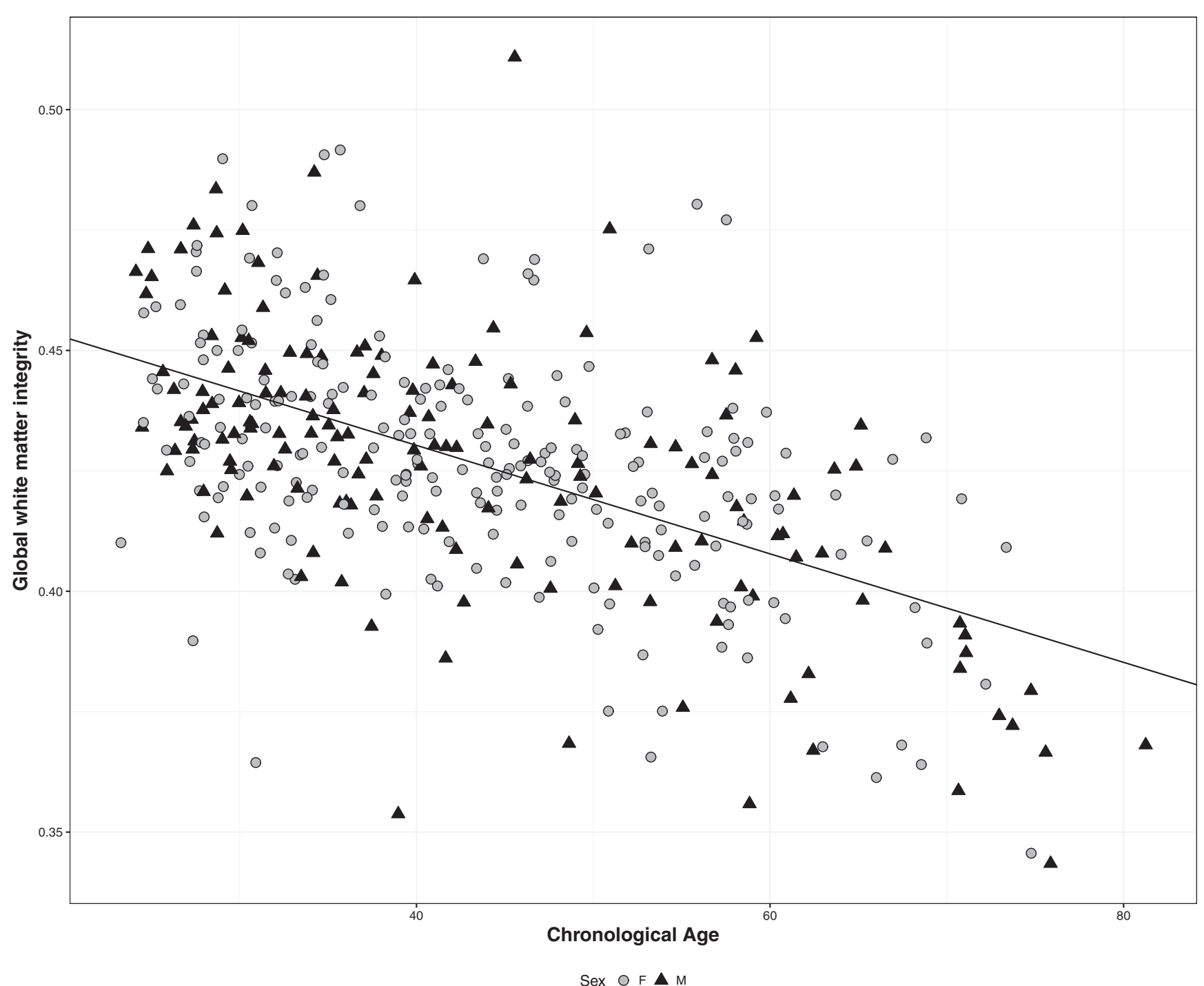

Figure 2. Relationship between chronological age and global white matter integrity. Light gray represents females. Dark gray represents males.

correlations where $p<0.05$ (i.e., all traits except the posterior thalamic radiation and superior frontal-occipital fasciculus). In each case, the genetic correlation was negative, as with the global FA measure.

Only the anterior corona radiata shows evidence of shared environmental influences with age acceleration $\left(\rho_{\text {environ }}=0.428\right.$, $p=0.013$ ), but in this case the relationship is positive, indicating that environments that are linked to increased epigenetic age acceleration are also associated with increased white matter integrity in this tract.

\section{White matter hyperintensity}

There is evidence that white matter hyperintensity lesions may also track with age. However, in our sample, there was not a linear relationship with age across adulthood; instead, we observed that larger hyperintensity volumes only appear beyond the fifth decade of life (Fig. 3), in line with previous findings (Habes et al., 2016). Reflecting this, the phenotypic correlation with age, while still highly significant $\left(\rho_{\text {pheno }}=0.426, p=1.12 \times 10^{-15}\right)$, is lower for white matter hyperintensity volume than for white matter integrity. Reflecting this weaker relationship with age across adulthood, the phenotypic correlation between white matter hy- perintensity volume and epigenetic age acceleration is not significant $\left(\rho_{\text {pheno }}=0.097, p=0.063\right)$.

\section{Cell count estimates}

In light of a previous study, which observed that both epigenetic age acceleration and granulocyte cell counts are related to Parkinson's disease (Horvath and Ritz, 2015), we undertook a secondary analysis examining the relationship between cell count estimates and our phenotypes of interest (Table 2).

Briefly, we find that the phenotypic correlations between cell counts and epigenetic age acceleration broadly reflect those seen with age in this sample. When considering cell counts in relation to global white matter tract integrity, the strongest phenotypic correlation that we see is with granulocyte count, which is negative in direction $\left(\rho_{\text {pheno }}=-0.170\right.$, $\left.p=1.29 \times 10^{-3}\right)$. The effect appears to be independent of any age- or epigenetic age acceleration-related effects.

\section{Discussion}

Both epigenetic age acceleration and white matter tract integrity traits are heritable in this sample, with estimates aligning closely with previous findings (Horvath, 2013; Jahanshad et al., 2013; 


\begin{tabular}{|c|c|c|c|c|c|c|c|c|c|c|c|c|c|}
\hline \multirow{3}{*}{ DTI trait } & & & & \multirow{2}{*}{\multicolumn{3}{|c|}{ Chronological age }} & \multicolumn{7}{|c|}{ Epigenetic age acceleration } \\
\hline & & & & & & & \multirow{2}{*}{\multicolumn{3}{|c|}{ Phenotypic correlation }} & \multirow{2}{*}{\multicolumn{2}{|c|}{ Genetic correlation }} & \multirow{2}{*}{\multicolumn{2}{|c|}{$\begin{array}{l}\text { Environmental } \\
\text { correlation }\end{array}$}} \\
\hline & \multicolumn{3}{|c|}{ Heritability } & \multicolumn{3}{|c|}{ Phenotypic correlation } & & & & & & & \\
\hline Global white-matter tract integrity & $0.506^{*}$ & $1.65 \mathrm{E}-05^{*}$ & NA & $-0.542^{*}$ & $5.13 \mathrm{E}-32^{*}$ & NA & $-0.119^{*}$ & $0.028^{*}$ & NA & $-0.463^{*}$ & $0.013^{*}$ & 0.213 & 0.223 \\
\hline Corpus callosum (body) & $0.502^{*}$ & $1.12 \mathrm{E}-05^{*}$ & $2.24 \mathrm{E}-05^{*}$ & $-0.464^{*}$ & $1.06 \mathrm{E}-22^{*}$ & $3.39 \mathrm{E}-22^{*}$ & $-0.167^{*}$ & $0.002^{*}$ & $0.011^{*}$ & $-0.571^{*}$ & $1.35 \mathrm{E}-03^{*}$ & 0.243 & 0.102 \\
\hline Corona radiata (posterior) & $0.470^{*}$ & $6.70 \mathrm{E}-06^{*}$ & $1.53 \mathrm{E}-05^{*}$ & $-0.458^{*}$ & $6.94 \mathrm{E}-22^{*}$ & $1.23 \mathrm{E}-21^{*}$ & $-0.166^{*}$ & $0.002^{*}$ & $0.011^{*}$ & $-0.512^{*}$ & 4.67E-03* & 0.153 & 0.307 \\
\hline Corpus callosum (genu) & $0.666^{*}$ & $4.00 \mathrm{E}-07^{*}$ & $2.13 \mathrm{E}-06^{*}$ & $-0.459^{*}$ & $2.61 \mathrm{E}-22^{*}$ & $6.13 \mathrm{E}-22^{*}$ & $-0.112^{*}$ & $0.037^{*}$ & $0.091^{*}$ & $-0.453^{*}$ & 7.32E-03* & 0.375 & 0.072 \\
\hline Posterior thalamic radiation & $0.450^{*}$ & $5.49 \mathrm{E}-05^{*}$ & 7.99E-05* & $-0.502^{*}$ & $2.41 \mathrm{E}-26^{*}$ & $1.29 \mathrm{E}-25^{*}$ & $-0.114^{*}$ & $0.036^{*}$ & $0.091^{*}$ & -0.329 & 0.107 & 0.009 & 0.703 \\
\hline Superior frontal-occipital fasciculus & $0.521^{*}$ & $6.00 \mathrm{E}-07^{*}$ & $2.40 \mathrm{E}-06^{*}$ & $-0.393^{*}$ & 1.77E-15* & $2.18 \mathrm{E}-15^{*}$ & $-0.109^{*}$ & $0.04^{*}$ & $0.091^{*}$ & -0.333 & 0.072 & 0.086 & 0.561 \\
\hline Corona radiata (superior) & $0.634^{*}$ & $1.00 \mathrm{E}-07^{*}$ & $1.60 \mathrm{E}-06^{*}$ & $-0.398^{*}$ & $1.38 \mathrm{E}-15^{*}$ & $1.84 \mathrm{E}-15^{*}$ & -0.064 & 0.226 & 0.278 & - & - & - & - \\
\hline Sagittal stratum & $0.378^{*}$ & $1.26 \mathrm{E}-03^{*}$ & $1.44 \mathrm{E}-03^{*}$ & $-0.464^{*}$ & $2.68 \mathrm{E}-22^{*}$ & $6.13 \mathrm{E}-22^{*}$ & -0.091 & 0.097 & 0.162 & - & - & - & - \\
\hline Internal capsule (retrolenticular) & $0.410^{*}$ & $6.61 \mathrm{E}-04^{*}$ & $8.14 \mathrm{E}-04^{*}$ & $-0.434^{*}$ & $5.74 \mathrm{E}-19^{*}$ & 8.35E-19* & -0.096 & 0.082 & 0.162 & - & - & - & - \\
\hline External capsule & $0.583^{*}$ & $3.70 \mathrm{E}-06^{*}$ & $9.87 \mathrm{E}-06^{*}$ & $-0.544^{*}$ & $2.47 \mathrm{E}-25^{*}$ & $9.88 \mathrm{E}-25^{*}$ & -0.048 & 0.431 & 0.46 & - & - & - & - \\
\hline Internal capsule (posterior limb) & $0.331^{*}$ & $9.77 \mathrm{E}-03 *$ & 9.77E-03* & $-0.308^{*}$ & $1.06 \mathrm{E}-09^{*}$ & 1.13E-09* & -0.022 & 0.63 & 0.63 & - & - & - & - \\
\hline
\end{tabular}

${ }^{a}$ The primary outcome was global white matter tract integrity. Further investigation was then undertaken to look at the 16 specific DTI tracts available; an FDR threshold was applied across these 16 traits. Decomposition of phenotypic correlations with epigenetic age acceleration into genetic and environmental influences is shown for all traits where phenotypic correlations $p<0.05$. No decomposition was undertaken for phenotypic correlations with chronological age as this is not heritable.

${ }^{*} p<0.05$.

Kochunov et al., 2015; Marioni et al., 2015a). We observe negative phenotypic correlations between these two traits both globally and within a number of specific white matter tracts in the brain. Decomposition of each of these phenotypic correlations reveals negative genetic correlations between epigenetic age acceleration and white matter integrity. Only one white matter tract (anterior corona radiata) showed significant (positive) environmental correlation with epigenetic age acceleration. Therefore, our results show that, when epigenetic age estimates in blood are older than would be expected, this is associated with reduced white matter tract integrity, and there are common genetic influences acting on both phenotypes.

While the relationship between age acceleration and tract integrity did not reach significance for a number specific white matter tracts tested, all showed the same pattern of negative phenotypic correlations with epigenetic age acceleration, suggesting that further examination in larger samples with greater statistical power would be of interest to establish whether the observed relationship with epigenetic age acceleration is global or focused in specific brain tracts.

In either case, these phenotypic and genetic correlations provide an interesting window into the neurobiology of aging processes within the brain. While the observed pleiotropic influences provide a causal genetic anchor linking epigenetic age acceleration with white matter integrity, evidence of genetic correlation is not sufficient to determine the processes that link these two traits, there are number of possible causal models that could be underlie this shared genetic etiology. Further work is necessary to determine the biological pathways linking these two processes and lead toward the delineation of the mechanisms involved in normal and pathological brain aging. Identification of the specific genes involved offers a useful starting point.

In terms of the biological meaning of the epigenetic age estimation, Horvath (2013) suggests that, as the measure seems to be distinct from cellular senescence and mitotic age, the epigenetic clock captures work done by an epigenetic maintenance system, which works to maintain epigenetic stability. Further work also shows that telomere length changes are also independent of changes in the epigenetic clock (Breitling et al., 2016; Lowe et al., 2016; Marioni et al., 2016).

Looking beyond cellular processes, epigenetic age acceleration has also been indicated as a biomarker for a number of other age-related traits; for example, among older individuals, relationships between accelerated epigenetic aging in blood and physical fitness, cognitive fitness, Parkinson's disease, and all-cause mortality have been reported (Horvath and Ritz, 2015; Marioni et al., 2015a, b; Chen et al., 2016). In samples that span adulthood, associations between epigenetic age acceleration in the blood and stress exposure and post-traumatic stress disorder have also been found (Boks et al., 2015; Zannas et al., 2015).

In this study, we also assess epigenetic aging in the blood with reference to brain-based traits. There have been several studies looking at different disorders linked to accelerated aging (including Huntingdon's disease, Down's syndrome, and HIV infection) that have shown the relationship to increased epigenetic aging can be seen in both blood and brain tissue samples (Horvath and Levine, 2015; Horvath et al., 2015a, 2016b). When multiple samples from the same individual have been available for comparison, there has been good consistency between epigenetic age estimates from different tissues, including blood and brain (Horvath, 2013; Horvath et al., 2015b). Additionally, evidence indicates that there is high convergence between epigenetic profiles in different tissues from the same individual, and correlations between blood and brain methylation levels are notably higher than those observed for gene expression (Horvath et al., 2012; Horvath, 2013).

Nevertheless, there are also examples of tissue-specific accelerated aging processes (Horvath et al., 2014). The phenotypic correlations reported here are modest; their magnitude is comparable with that previously reported between epigenetic age acceleration as mea- 


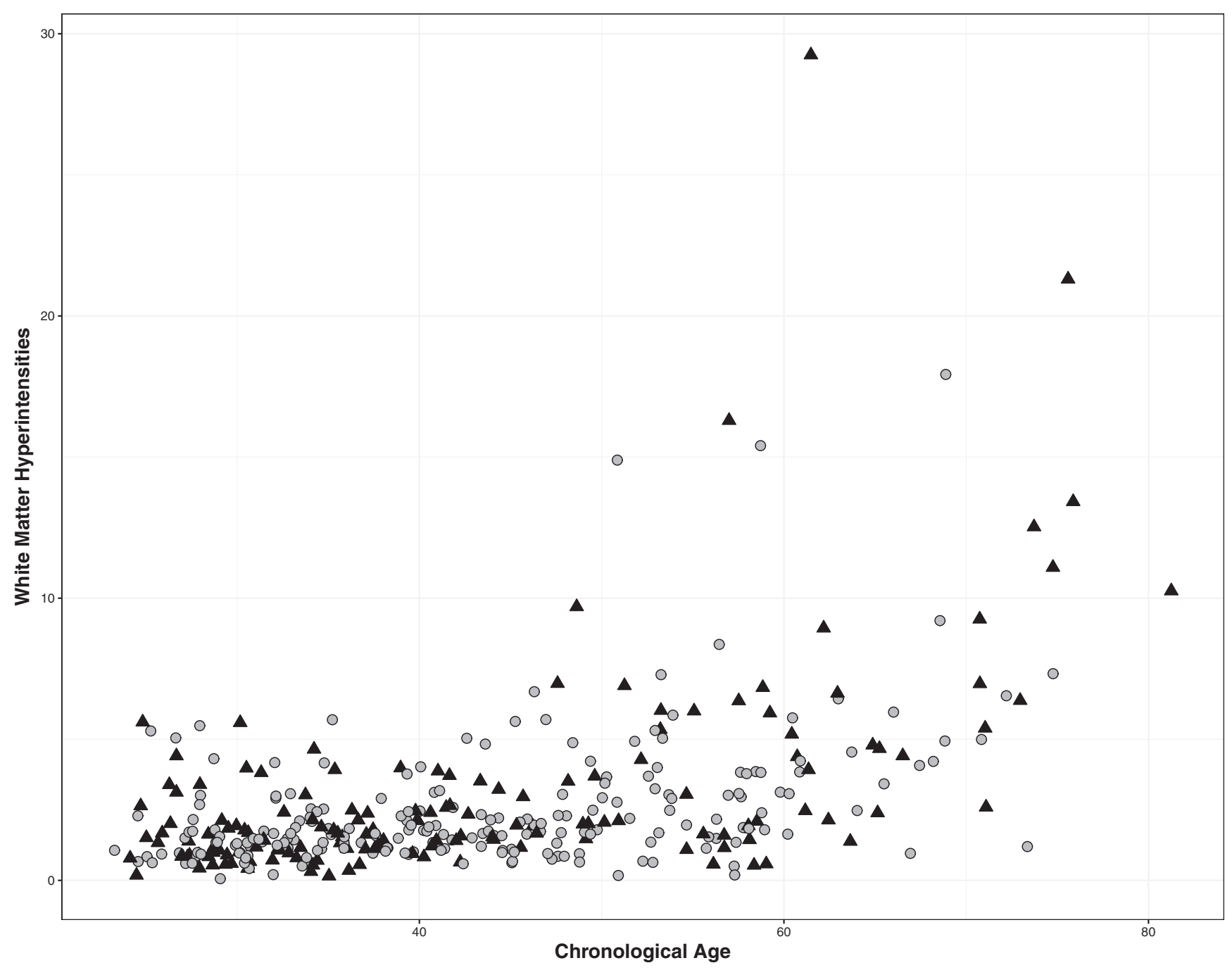

Sex OF $\boldsymbol{\Delta} M$

Figure 3. Relationship between chronological age and white matter hyperintensity volume. Light gray represents females. Dark gray represents males.

Table 2. Cell abundance estimations and correlations with traits of interest ${ }^{a}$

\begin{tabular}{|c|c|c|c|c|c|c|c|c|c|c|c|c|c|c|c|c|c|c|c|c|}
\hline \multirow[b]{3}{*}{ Cell types } & & & & \multirow{2}{*}{\multicolumn{3}{|c|}{ Chronological age }} & \multicolumn{7}{|c|}{ Epigenetic age acceleration } & \multicolumn{7}{|c|}{ Global white-matter tract integrity } \\
\hline & \multicolumn{3}{|c|}{ Heritability } & & & & \multicolumn{3}{|c|}{ Phenotypic correlation } & \multicolumn{2}{|c|}{$\begin{array}{l}\text { Genetic } \\
\text { correlation }\end{array}$} & \multicolumn{2}{|c|}{$\begin{array}{l}\text { Environmental } \\
\text { correlation }\end{array}$} & \multicolumn{3}{|c|}{ Phenotypic correlation } & \multicolumn{2}{|c|}{$\begin{array}{l}\text { Genetic } \\
\text { correlation }\end{array}$} & \multicolumn{2}{|c|}{$\begin{array}{l}\text { Environmental } \\
\text { correlation }\end{array}$} \\
\hline & $h^{2}$ & $p$ & FDR & $\rho$ & $p$ & FDR & $\rho$ & $p$ & FDR & $\rho$ & $p$ & $\rho$ & $p$ & $\rho$ & $p$ & FDR & $\rho$ & $p$ & $\rho$ & $p$ \\
\hline Naive CD8 T & $0.628^{*}$ & $5.45 E-15^{*}$ & $1.91 \mathrm{E}-14^{*}$ & $-0.580^{*}$ & $4.43 \mathrm{E}-67^{*}$ & $3.10 \mathrm{E}-66^{*}$ & $-0.146^{*}$ & $9.17 \mathrm{E}-04^{*}$ & $2.14 \mathrm{E}-03^{*}$ & 0.010 & 0.950 & $-0.312^{*}$ & $0.014^{*}$ & 0.091 & 0.111 & 0.155 & - & - & - & - \\
\hline CD4 T & $0.359^{*}$ & $2.80 \mathrm{E}-06^{*}$ & $2.80 \mathrm{E}-06^{*}$ & $-0.117^{*}$ & $3.27 \mathrm{E}-03^{*}$ & $5.72 \mathrm{E}-03^{*}$ & $-0.164^{*}$ & $1.05 \mathrm{E}-04^{*}$ & $7.35 \mathrm{E}-04^{*}$ & -0.059 & 0.780 & $-0.219^{*}$ & $0.029^{*}$ & $0.105^{*}$ & $0.043^{*}$ & $0.086^{*}$ & 0.135 & 0.521 & 0.085 & 0.565 \\
\hline Granulocytes & $0.519^{*}$ & $1.61 \mathrm{E}-11^{*}$ & $2.82 \mathrm{E}-11^{*}$ & 0.015 & 0.712 & 0.712 & 0.010 & 0.814 & 0.814 & - & - & - & - & $-0.170^{*}$ & $1.29 \mathrm{E}-03^{*}$ & $9.03 \mathrm{E}-03^{*}$ & -0.292 & 0.125 & -0.049 & 0.758 \\
\hline Monocytes & $0.394^{*}$ & $6.00 \mathrm{E}-07^{*}$ & $7.00 \mathrm{E}-07^{*}$ & 0.072 & 0.072 & 0.101 & 0.046 & 0.274 & 0.320 & - & - & - & - & -0.024 & 0.658 & 0.658 & - & - & - & - \\
\hline Natural killer & $0.656^{*}$ & $3.27 E-24^{*}$ & $2.29 \mathrm{E}-23^{*}$ & $0.342^{*}$ & $1.49 \mathrm{E}-23^{*}$ & $5.22 \mathrm{E}-23^{*}$ & 0.053 & 0.214 & 0.300 & - & - & - & - & $0.116^{*}$ & $0.026^{*}$ & $0.086^{*}$ & 0.214 & 0.160 & -0.010 & 0.952 \\
\hline Plasmablast & $0.512^{*}$ & $1.97 \mathrm{E}-12^{*}$ & $4.60 \mathrm{E}-12^{*}$ & 0.016 & 0.683 & 0.712 & 0.066 & 0.124 & 0.217 & - & - & - & - & $-0.108^{*}$ & $0.049^{*}$ & $0.086^{*}$ & -0.264 & 0.168 & 0.044 & 0.780 \\
\hline $\begin{array}{l}\text { CD8 + } \\
\quad \text { CD28- } \\
\text { CD45RA-T }\end{array}$ & $0.410^{*}$ & $1.00 \mathrm{E}-07^{*}$ & 1.40E-07* & $0.306^{*}$ & 9.06E-15* & 2.11E-14* & $0.149^{*}$ & $4.02 E-04^{*}$ & 1.41E-03* & 0.193 & 0.339 & 0.125 & 0.206 & -0.045 & 0.398 & 0.464 & - & - & - & - \\
\hline
\end{tabular}

${ }^{a} \mathrm{An} \mathrm{FDR}$ correction was applied across the 7 cell types considered. Phenotypic correlations between cell abundances and epigenetic age acceleration or global white matter tract integrity were decomposed into genetic and environmenta influences when phenotypic correlations $p<0.05$. No decomposition was undertaken for phenotypic correlations with chronological age as this is not heritable.

${ }^{*} p<0.05$.

sured in dorsolateral prefrontal cortex tissue and neuropathological measures associated with Alzheimer's disease (Levine et al., 2015). Given examples of tissue-specific accelerated aging, it could be speculated that stronger associations between epigenetic age acceleration and white matter integrity might be observed if age acceleration was measured using brain tissue rather than blood. However, there is a distinct advantage in being able to use an easily accessible tissue, such as blood, for this potential biomarker of healthy and pathological brain aging, including that the biomarker can be assessed at multiple points throughout the lifespan. 
The evidence to date suggests that, although there may be some pathological processes leading to tissue-specific age acceleration, in general blood can serve as a useful surrogate tissue for the development of aging biomarkers, particularly when the most relevant tissue is not easily accessible, as is the case when looking at brain traits.

We also performed a secondary analysis examining cell count estimates in the blood and how these relate to both age and white matter integrity. We find a negative correlation between granulocytes and white matter integrity that is independent of agerelated effects. This pattern of results echoes the relationship observed previously in Parkinson's disease using similar methods, whereby patients were observed to not only show increased epigenetic accelerated aging but also have more granulocytes than controls (Horvath and Ritz, 2015). Although we are unable to distinguish between granulocyte subtypes, given that neutrophils are far more prevalent than eosinophils or basophils (accounting for $60 \%-70 \%, 2 \%-4 \%$, and $0.5 \%-1 \%$ of white blood cells, respectively), it is likely that they are driving the observed association. But clearly, further work is needed to understand this relationship with white matter integrity. As we are using indirectly estimating relative cell abundance measures from epigenetic data, replication with direct measurements of cell types is also needed.

In conclusion, acceleration in epigenetic aging shows negative phenotypic and genetic correlations with white matter integrity both globally and within a number of specific tracts within the brain. This suggests that the epigenetic clock may prove a useful biomarker of normal and pathological brain aging across the adult lifespan. The shared genetic influences on these two traits offer a method by which researchers can begin to unpick the neurobiological processes underpinning variation in age-related changes in the brain.

\section{References}

Benjamini Y, Hochberg Y (1995) Controlling the false discovery rate: a practical and powerful approach to multiple testing. J R Stat Soc Ser B 57:289-300.

Bishop NA, Lu T, Yankner BA (2010) Neural mechanisms of ageing and cognitive decline. Nature 464:529-535. CrossRef Medline

Boks MP, van Mierlo HC, Rutten BP, Radstake TR, De Witte L, Geuze E, Horvath S, Schalkwyk LC, Vinkers CH, Broen JC. Vermetten E (2015) Longitudinal changes of telomere length and epigenetic age related to traumatic stress and post-traumatic stress disorder. Psychoneuroendocrinology 51:506-512. CrossRef Medline

Breitling LP, Saum KU, Perna L, Schöttker B, Holleczek B, Brenner H (2016) Frailty is associated with the epigenetic clock but not with telomere length in a German cohort. Clin Epigenetics 8:21. CrossRef Medline

Chen BH, Marioni RE, Colicino E, Peters, MJ, Ward-Caviness CK, Tsai PC, Roetker NS, Just AC, Demerath EW, Guan W, Bressler J, Fornage M, Studenski S, Vandiver AR, Moore AZ, Tanaka T, Kiel DP, Liang L, Volkonas P, Schwartz J, et al (2016) DNA methylation-based measures of biological age: meta-analysis predicting time to death. Aging (Albany, NY) 8:1844-1865. CrossRef Medline

Cox SR, Ritchie SJ, Tucker-Drob EM, Liewald DC, Hagenaars SP, Davies G, Wardlaw JM, Gale CR, Bastin ME, Deary IJ (2016) Ageing and brain white matter structure in 3,513 UK Biobank participants. Nat Commun 7:13629. CrossRef Medline

Fraga MF, Ballestar E, Paz MF, Ropero S, Setien F, Ballestar ML, Heine-Suñer D, Cigudosa JC, Urioste M, Benitez J, Boix-Chornet M, Sanchez-Aguilera A, Ling C, Carlsson E, Poulsen P, Vaag A, Stephan Z, Spector TD, Wu YZ, Plass C, et al (2005) Epigenetic differences arise during the lifetime of monozygotic twins. Proc Natl Acad Sci U S A 102:10604-10609. CrossRef Medline

Giorgio A, Santelli L, Tomassini V, Bosnell R, Smith S, De Stefano N, Johansen-Berg H (2010) Age-related changes in grey and white matter structure throughout adulthood. Neuroimage 51:943-951. CrossRef Medline

Glahn DC, Kent JW Jr, Sprooten E, Diego VP, Winkler AM, Curran JE, McKay DR, Knowles EE, Carless MA, Göring HH, Dyer TD, Olvera RL, Fox PT, Almasy L, Charlesworth J, Kochunov P, Duggirala R, Blangero J (2013) Genetic basis of neurocognitive decline and reduced white matter integrity in normal human brain aging. Proc Natl Acad Sci U S A 110: 19006-19011. CrossRef Medline

Habes M, Erus G, Toledo JB, Zhang T, Bryan N, Launer LJ, Rosseel Y, Janowitz D, Doshi J, Van der Auwera S, von Sarnowski B, Hegenscheid K, Hosten N, Homuth G, Völzke H, Schminke U, Hoffmann W, Grabe HJ, Davatzikos C (2016) White matter hyperintensities and imaging patterns of brain ageing in the general population. Brain 139:1164-1179. CrossRef Medline

Hannum G, Guinney J, Zhao L, Zhang L, Hughes G, Sadda S, Klotzle B, Bibikova M, Fan JB, Gao Y, Deconde R, Chen M, Rajapakse I, Friend S, Ideker T, Zhang K (2013) Genome-wide methylation profiles reveal quantitative views of human aging rates. Mol Cell 49:359-367. CrossRef Medline

Horvath S (2013) DNA methylation age of human tissues and cell types. Genome Biol 14:R115. CrossRef Medline

Horvath S, Gurven M, Levine ME, Trumble BC, Kaplan H, Allayee H, Ritz BR, Chen B, Lu AT, Rickabaugh TM, Jamieson BD, Sun D, Li S, Chen W, Quintana-Murci L, Fagny M, Kobor MS, Tsao PS, Reiner AP, Edlefsen KL, et al (2016a) An epigenetic clock analysis of race/ethnicity, sex, and coronary heart disease. Genome Biol 17:171. CrossRef Medline

Horvath S, Levine AJ (2015) HIV-1 infection accelerates age according to the epigenetic clock. J Infect Dis 212:1563-1573. CrossRef Medline

Horvath S, Ritz BR (2015) Increased epigenetic age and granulocyte counts in the blood of Parkinson's disease patients. Aging (Albany, NY) 7:11301142. CrossRef Medline

Horvath S, Zhang Y, Langfelder P, Kahn RS, Boks MP, van Eijk K, van den Berg LH, Ophoff RA (2012) Aging effects on DNA methylation modules in human brain and blood tissue. Genome Biol 13:R97. CrossRef Medline

Horvath S, Erhart W, Brosch M, Ammerpohl O, von Schönfels W, Ahrens M, Heits N, Bell JT, Tsai PC, Spector TD, Deloukas P, Siebert R, Sipos B, Becker T, Röcken C, Schafmayer C, Hampe J (2014) Obesity accelerates epigenetic aging of human liver. Proc Natl Acad Sci U S A 111:1553815543. CrossRef Medline

Horvath S, Garagnani P, Bacalini MG, Pirazzini C, Salvioli S, Gentilini D, Di Blasio AM, Giuliani C, Tung S, Vinters HV, Franceschi C (2015a) Accelerated epigenetic aging in Down syndrome. Aging Cell 14:491-495. CrossRef Medline

Horvath S, Mah V, Lu AT, Woo JS, Choi OW, Jasinska AJ, Riancho JA, Tung S, Coles NS, Braun J, Vinters HV, Coles LS (2015b) The cerebellum ages slowly according to the epigenetic clock. Aging (Albany NY) 7:294-306. CrossRef Medline

Horvath S, Langfelder P, Kwak S, Aaronson J, Rosinski J, Vogt TF, Eszes M, Faull RL, Curtis MA, Waldvogel HJ, Choi OW, Tung S, Vinters HV, Coppola G, Yang XW (2016b) Huntington's disease accelerates epigenetic aging of human brain and disrupts DNA methylation levels. Aging (Albany NY) 8:1485-1512. CrossRef Medline

Houseman EA, Accomando WP, Koestler DC, Christensen BC, Marsit CJ, Nelson HH, Wiencke JK, Kelsey KT (2012) DNA methylation arrays as surrogate measures of cell mixture distribution. BMC Bioinformatics 13: 86. CrossRef Medline

Jahanshad N, Kochunov PV, Sprooten E, Mandl RC, Nichols TE, Almasy L, Blangero J, Brouwer RM, Curran JE, de Zubicaray GI, Duggirala R, Fox PT, Hong LE, Landman BA, Martin NG, McMahon KL, Medland SE, Mitchell BD, Olvera RL, Peterson CP, et al (2013) Multi-site genetic analysis of diffusion images and voxelwise heritability analysis: a pilot project of the ENIGMA-DTI working group. Neuroimage 81:455-469. CrossRef Medline

Jones MJ, Goodman SJ, Kobor MS (2015) DNA methylation and healthy human aging. Aging Cell 14:924-932. CrossRef Medline

Kochunov P, Jahanshad N, Marcus D, Winkler A, Sprooten E, Nichols TE, Wright SN, Hong LE, Patel B, Behrens T, Jbabdi S, Andersson J, Lenglet C, Yacoub E, Moeller S, Auerbach E, Ugurbil K, Sotiropoulos SN, Brouwer RM, Landman B, et al (2015) Heritability of fractional anisotropy in human white matter: a comparison of Human Connectome Project and ENIGMA-DTI data. Neuroimage 111:300-311. CrossRef Medline

Kochunov P, Glahn D, Lancaster J, Winkler A, Kent JW Jr, Olvera RL, Cole 
SA, Dyer TD, Almasy L, Duggirala R, Fox PT, Blangero J (2010) Whole brain and regional hyperintense white matter volume and blood pressure: overlap of genetic loci produced by bivariate, whole-genome linkage analyses. Stroke 41:2137-2142. CrossRef Medline

Kulkarni H, Kos MZ, Neary J, Dyer TD, Kent JW Jr, Göring HH, Cole SA, Comuzzie AG, Almasy L, Mahaney MC, Curran JE, Blangero J, Carless MA (2015) Novel epigenetic determinants of type 2 diabetes in Mexican-American families. Hum Mol Genet 24:5330-5344. CrossRef Medline

Levine ME, Lu AT, Bennett DA, Horvath S (2015) Epigenetic age of the pre-frontal cortex is associated with neuritic plaques, amyloid load, and Alzheimer's disease related cognitive functioning. Aging (Albany NY) 7:1198-1211. CrossRef Medline

Lowe D, Horvath S, Raj K (2016) Epigenetic clock analyses of cellular senescence and ageing. Oncotarget 7:8524-8531. CrossRef Medline

Lu AT, Hannon E, Levine ME, Hao K, Crimmins EM, Lunnon K, Kozlenkov A, Mill J, Dracheva S, Horvath S (2016) Genetic variants near MLST8 and DHX57 affect the epigenetic age of the cerebellum. Nat Commun 7:10561. CrossRef Medline

Marioni RE, Shah S, McRae AF, Chen BH, Colicino E, Harris SE, Gibson J, Henders AK, Redmond P, Cox SR, Pattie A, Corley J, Murphy L, Martin NG, Montgomery GW, Feinberg AP, Fallin MD, Multhaup ML, Jaffe AE, Joehanes R, et al (2015a) DNA methylation age of blood predicts allcause mortality in later life. Genome Biol 16:25. CrossRef Medline

Marioni RE, Shah S, McRae AF, Ritchie SJ, Muniz-Terrera G, Harris SE, Gibson J, Redmond P, Cox SR, Pattie A, Corley J, Taylor A, Murphy L, Starr JM, Horvath S, Visscher PM, Wray NR, Deary IJ (2015b) The epigenetic clock is correlated with physical and cognitive fitness in the Lothian Birth Cohort 1936. Int J Epidemiol 44:1388-1396. CrossRef Medline

Marioni RE, Harris SE, Shah S, McRae AF, von Zglinicki T, Martin-Ruiz C, Wray NR, Visscher PM, Deary IJ (2016) The epigenetic clock and telomere length are independently associated with chronological age and mortality. Int J Epidemiol. Advance online publication. Retrieved Apr. 13, 2016. doi: 10.1093/ije/dyw041. CrossRef Medline

Mather M, Jacobsen LA, Pollard KM (2015) Aging in the United States. Popul Bull 70.

Mitchell BD, Kammerer CM, Blangero J, Mahaney MC, Rainwater DL, Dyke B, Hixson JE, Henkel RD, Sharp RM, Comuzzie AG, VandeBerg JL, Stern MP, MacCluer JW (1996) Genetic and environmental contributions to cardiovascular risk factors in Mexican-Americans: the San Antonio Family Heart Study. Circulation 94:2159-2170. CrossRef Medline

Mori S, Oishi K, Jiang H, Jiang L, Li X, Akhter K, Hua K, Faria AV, Mahmood A, Woods R, Toga AW, Pike GB, Neto PR, Evans A, Zhang J, Huang H, Miller MI, van Zijl P, Mazziotta J (2008) Stereotaxic white matter atlas based on diffusion tensor imaging in an ICBM template. Neuroimage 40:570-582. CrossRef Medline
Moseley M (2002) Diffusion tensor imaging and aging: a review. NMR Biomed 15:553-560. CrossRef Medline

Olvera RL, Bearden CE, Velligan DI, Almasy L, Carless MA, Curran JE, Williamson DE, Duggirala R, Blangero J, Glahn DC (2011) Common genetic influences on depression, alcohol, and substance use disorders in Mexican-American families. Am J Med Genet B Neuropsychiatr Genet 156B:561-568. CrossRef Medline

Puppala S, Dodd GD, Fowler S, Arya R, Schneider J, Farook VS, Granato R, Dyer TD, Almasy L, Jenkinson CP, Diehl AK, Stern MP, Blangero J, Duggirala R (2006) A genomewide search finds major susceptibility loci for gallbladder disease on chromosome 1 in Mexican-Americans. Am J Hum Genet 78:377-392. CrossRef Medline

Smith SM, Jenkinson M, Johansen-Berg H, Rueckert D, Nichols TE, Mackay CE, Watkins KE, Ciccarelli O, Cader MZ, Matthews PM, Behrens TE (2006) Tract-based spatial statistics: voxelwise analysis of multi-subject diffusion data. Neuroimage 31:1487-1505. CrossRef Medline

Sprooten E, Knowles EE, McKay DR, Göring HH,Curran JE, Kent JW, Carless MA, Dyer TD, Drigalenko EI, Olvera RL, Fox PT, Almasy L, Duggirala R, Kochunov P, Blangero J, Glahn DC (2014) Common genetic variants and gene expression associated with white matter microstructure in the human brain. Neuroimage 97:252-261. CrossRef Medline

Sullivan EV, Pfefferbaum A (2006) Diffusion tensor imaging and aging. Neurosci Biobehav Rev 30:749-761. CrossRef Medline

Teipel SJ, Meindl T, Wagner M, Stieltjes B, Reuter S, Hauenstein KH, Filippi M, Ernemann U, Reiser MF, Hampel H (2010) Longitudinal changes in fiber tract integrity in healthy aging and mild cognitive impairment: a DTI follow-up study. J Alzheimers Dis 22:507-522. CrossRef Medline

Teschendorff AE, West J, Beck S (2013) Age-associated epigenetic drift: implications, and a case of epigenetic thrift? Hum Mol Genet 22:R7-R15. CrossRef Medline

United Nations Department of Economic and Social Affairs Population Division (2015) World Population Ageing 2015. New York: United Nations.

van Boxtel MP, Buntinx F, Houx PJ, Metsemakers JF, Knottnerus A, Jolles J (1998) The relation between morbidity and cognitive performance in a normal aging population. J Gerontol A Biol Sci Med Sci 53:M147-M154. Medline

Weidner CI, Lin Q, Koch CM, Eisele L, Beier F, Ziegler P, Bauerschlag DO, Jöckel KH, Erbel R, Mühleisen TW, Zenke M, Brümmendorf TH, Wagner W (2014) Aging of blood can be tracked by DNA methylation changes at just three CpG sites. Genome Biol 15:R24. CrossRef Medline

Zannas AS, Arloth J, Carrillo-Roa T, Iurato S, Röh S, Ressler KJ, Nemeroff CB, Smith AK, Bradley B, Heim C, Menke A, Lange JF, Brückl T, Ising M, Wray NR, Erhardt A, Binder EB, Mehta D (2015) Lifetime stress accelerates epigenetic aging in an urban, African American cohort: relevance of glucocorticoid signaling. Genome Biol 16:266. CrossRef Medline 